\title{
Statistical Analysis of the Relationship between Diabetes and Psychological Disorders in Children
}

\author{
Mohamed E. M. Abdelhafez* \\ College of Business Administration, Kuwait University \\ *Corresponding author: elwym@hotmail.com
}

\begin{abstract}
The main objective of this paper is to investigate the impact of diabetes on the psychological characteristics in children. The study investigated 302 children aged 7 to 13 years old who had diabetes type I in Kuwait. A questionnaire was administered to participants (Parents or Guardians) of diabetic children. The questionnaire has two parts; the first part has sociodemographic and clinical characteristics of the children and participants and the second part is the "strengths and difficulties questionnaire" (SDQ) [1]. The strengths and difficulties questionnaire (SDQ) was widely used for screening emotional and behavioral problems. Internal consistency of the sample and the strengths and difficulties questionnaire (SDQ) (Arabic version) were measured by Cronbach's alpha coefficient. The percentages of children whose scores are in the normal, borderline, and abnormal classes were calculated. The results indicate that regarding the mental health of the children, $69.1 \%$ were considered positive overall (55\% abnormal and $14.1 \%$ borderline). Correlation analysis on the item-subscale level revealed that all items had the highest correlations to their respective subscales of origin. Further, subscale-subscale and subscale-total correlations were calculated. The results show significant correlations between the five subscales of the SDQ. Each subscale correlated significantly $(\mathrm{p}<0.01)$ with every other subscale. A principal component analysis with varimax rotation was conducted to investigate the factorial structure of scales. A discriminant analysis was performed to classify the diabetic children into one of the three groups (Normal, borderline, and abnormal). The results show that $93.3 \%$ of the original grouped cases were correctly classified.
\end{abstract}

Keywords: diabetes, children, psychology, disorder, Kuwait

Cite This Article: Mohamed E. M. Abdelhafez, "Statistical Analysis of the Relationship between Diabetes and Psychological Disorders in Children.” American Journal of Applied Mathematics and Statistics, vol. 6, no. 1 (2018): 9-16. doi: 10.12691/ajams-6-1-3.

\section{Introduction}

Several studies have shown that children with diabetes are more likely to have emotional or behavioral problems than children who do not have diabetes. Diabetes affects the life style and overall psychological and physical characteristics of the children.

Relationship of diabetes to emotional or behavioral problems in adolescents has been investigated by many authors [2,3,4,5,6,7]. Roy and Lloyd, 2012 pointed out that people with Type I diabetes have depression rates up to three times higher than those without Type I diabetes.

In the present study, we investigate the relationship between Diabetes and Emotional and Behavioral Problems for children aged 7 to 13 years old who had diabetes in Kuwait.

\section{Methods}

The present study was conducted at Kuwait University, 2005. The sample comprised 302 children aged 7-13 years. Trained interviewers administered questionnaires to Participants (parents and caretakers) at a governmental hospital.
The questionnaire consists of two parts; the first part has demographic and clinical characteristics of the children and participants and the second part is the "strengths and difficulties questionnaire" (SDQ) [1]. The demographic and clinical characteristics included respondent gender, child gender, child age, respondent nationality, respondent age, respondent education, child education, family income, duration of diabetes (in years), type of diabetes, does any of the parents have diabetes, the number of brothers who have diabetes, the number of times the child entered the hospital because of diabetes, and the Hemoglobin level.

The strengths and difficulties questionnaire (SDQ) is widely used as a useful tool for screening emotional and behavioral problems in children aging 4-16 years [8-18]. The SDQ has been translated into more than 60 languages, being available in the internet at www.sdqinfo.com. The structure, reliability, validity, and psychometric properties of the strengths and difficulties questionnaire (SDQ) have been extensively evaluated in different countries [8,19-36].

The SDQ has 25 items, some are positive and some are negative. The 25 items in the SDQ comprise five subscales of 5 items each. The five subscales are emotional symptoms, conduct problems, hyperactivity, peer problems, and prosocial behavior.

Each of the 25 items is marked as "Not true", "Somewhat true" or "Certainly true". Except for five 
positive items, written in bold, the scores for each item are 0 for "Not true", 1 for "Somewhat true" and 2 for "Certainly true". The five positive items, written in bold, are scored in the opposite direction, 2 for "Not true", 1 for "Somewhat true" and 0 for "Certainly true". The sum of the scores of each subscale ranges from 0 to 10 . The sum of the scores of the first four subscales of the SDQ gives a total difficulties score, ranging from 0 to 40 . High scores for each of the first four subscales indicate difficulties, whereas high scores on the prosocial subscale indicate strengths. The author of the SDQ classified scores for each of the subscales and for the total difficulties as normal, borderline and abnormal (clinical). According to the author of the instrument the cut-offs for 'high' scores for each sub-scale were as follows: conduct problems $\geq 4$, hyperactivity $\geq 7$, peer relationships $\geq 4$, emotional symptoms $\geq 5$ and prosocial behavior $\leq 4$. A 'high total difficulties score was defined as $\geq 17$. In the present study, abnormal and borderline cases were considered positive for mental health problems.

Table 1. Endorsement rates (\%) of response categories on each item

\begin{tabular}{|c|c|c|c|}
\hline & $\begin{array}{l}\text { Not } \\
\text { true }\end{array}$ & $\begin{array}{l}\text { Somewhat } \\
\text { true }\end{array}$ & $\begin{array}{l}\text { Certainly } \\
\text { true }\end{array}$ \\
\hline \multicolumn{4}{|l|}{ Prosocial subscale } \\
\hline Care about & 8.9 & 23.8 & 67.2 \\
\hline Easy to share & 27.5 & 16.9 & 55.6 \\
\hline Help other & 4.3 & 17.5 & 78.1 \\
\hline Friendly with younger & 7.6 & 16.2 & 76.2 \\
\hline Volunteer to help others & 3.7 & 13.6 & 82.7 \\
\hline \multicolumn{4}{|l|}{ Emotional subscale } \\
\hline $\begin{array}{l}\text { Extremely complains from } \\
\text { headache }\end{array}$ & 31.2 & 28.2 & 40.5 \\
\hline Worried & 34.4 & 27.5 & 38.1 \\
\hline Unhappy child & 29.8 & 11.3 & 58.9 \\
\hline Nervous & 21.5 & 22.8 & 55.6 \\
\hline Easily scared & 34.8 & 14.9 & 50.3 \\
\hline \multicolumn{4}{|l|}{ Conduct subscale } \\
\hline Easy to be angry & 10.6 & 21.6 & 67.8 \\
\hline Obedient & 15 & 29.3 & 55.7 \\
\hline Fights with others & 51.3 & 16.9 & 31.8 \\
\hline Lies and cheats & 34.4 & 14.6 & 51 \\
\hline Steals from home, school & 83.1 & 4.6 & 12.3 \\
\hline \multicolumn{4}{|l|}{ Hyperactivity subscale } \\
\hline Cannot stability in one place & 20.5 & 21.2 & 58.3 \\
\hline Move his body & 44 & 20.2 & 35.8 \\
\hline Little concentrate & 50.8 & 17.9 & 31.2 \\
\hline Thinks before behave & 33.1 & 28.5 & 38.4 \\
\hline Good attention & 35.1 & 14.6 & 50.3 \\
\hline \multicolumn{4}{|l|}{ Peer subscale } \\
\hline Loneliness & 78.4 & 13.3 & 8.3 \\
\hline Has at least one good friend & 5.6 & 6.6 & 87.7 \\
\hline Liked by other children & 2 & 7.6 & 90.4 \\
\hline Ridicule from other children & 67.9 & 10.9 & 21.2 \\
\hline Best conformity with adults & 55 & 12.3 & 32.8 \\
\hline
\end{tabular}

Table 1 shows the response rates of the SDQ items. The respondents had a tendency to choose the alternatives "not true" and "certainly true". This tendency was emphasized on the prosocial scale (55.6-82.7\% were rated "certainly true) and the positively worded problem items which were rated "certainly true" by (55.7\%, 38.4, 50.3, 87.7, 90.4\%) of the respondents. on the prosocial scale, the items that most often rated "certainly true" were " Volunteer to help others" (82.7\%), "Help other" (78.1\%), and " Friendly with younger" (76.2\%). On the emotional scale, the items that are most often rated "certainly true" are "unhappy child" (58.9\%), "nervous" (55.6\%), and "easily scared" (50.3\%). On the conduct scale items, the most common problems are "Easy to be angry" (67.8\%), "Lies and cheats" (51\% ), and "fight with others" (31.8\%). Of the hyperactivity problem items, "cannot be stable" was most often rated "certainly true" (58.3\%).

The following table shows the percentages of boys and girls and total percentages of children whose scores are in the normal, borderline, and abnormal classes.

Table 2. Percentage of Children in Normal, Borderline, and Abnormal Groups

\begin{tabular}{|l|c|c|c|}
\hline Scale & $\begin{array}{c}\text { Normal } \\
\text { (\%) }\end{array}$ & $\begin{array}{c}\text { Borderline } \\
(\%)\end{array}$ & $\begin{array}{c}\text { Abnormal } \\
(\%)\end{array}$ \\
\hline Total Difficulties Score & 24.1 & 17.5 & 58.4 \\
Boys & 36.6 & 11.2 & 52.2 \\
Girls & 30.9 & 14.1 & 55 \\
Total & & & \\
\hline Emotional Problems & 20.9 & 9.4 & 69.8 \\
Boys & 14.9 & 11.8 & 73.3 \\
Girls & 17.7 & 10.7 & 71.7 \\
Total & & & \\
\hline Conduct Problems & 23.2 & 12.3 & 64.5 \\
Boys & 27.3 & 12.4 & 60.2 \\
Girls & 25.4 & 12.4 & 62.2 \\
Total & & & \\
\hline Hyperactivity & 47.9 & 25 & 27.1 \\
Boys & 64.6 & 14.3 & 21.1 \\
Girls & 56.8 & 19.3 & 23.9 \\
Total & & & 18.3 \\
\hline Peer Problems & 70.2 & 9.3 & 2.9 \\
Boys & 90.7 & 10.7 & 4 \\
Girls & 91.7 & 4.3 & \\
Total & & & \\
\hline Prosocial & & & \\
Boys & & & \\
Girls & & & \\
Total & & & \\
\hline
\end{tabular}

According to the total difficulties scores, the results showed that $69.1 \%$ of the children have overall mental health problems (55\% abnormal and $14.1 \%$ borderline). The highest percentage (82.4\%) was for the emotional problems whereas the lowest percentage (30\%) was for peer relationship problems. In the present study, abnormal and borderline cases were considered positive for psychological problems.

The study comprised 302 respondents, (75.8\%) citizen and (24.2\%) non-citizen; (32.1\%) males and (67.9\%) females. The age of the respondents ranges from 17 to 75 year-old and the respondent education ranges from elementary school (7\%), intermediate (21\%), high school (20.3\%), Diploma (19.7\%), university level (31.7\%) to master level (0.3\%). Family income ranges from less than $500 \mathrm{KD}$ (15.6\%), 500-700 KD (17.3), 701-900 KD (14.6\%), 901-1100 KD (9\%) to more than $1101 \mathrm{KD}$ (43.5\%).

The total sample of children was 302: (53.5\%) girls and (46.5\%) boys. The child age ranges from 7 to 13 years old with mean 10.2 years and SD (2.1). The child education 
ranges from elementary (49\%), intermediate (50\%), and high school (0.7\%); the duration of diabetes (in years) ranges from 0 to 11 years with a mean of 3.52 years and a standard deviation of 2.343 years. Of the total sample of children (19.9\%) with diabetic parents and (80.1\%) their parents were not diabetic. The number of times the child entered the hospital because of high or low diabetes ranges from none (12.3\%), (53.8\%), 2-3 times (16.6\%), 4-5 times $(7.6 \%)$, to 6 or more times $(9.6 \%)$. The hemoglobin readings range from 3 to 32 with a mean of 12.97 and a standard deviation of 5.88. Except two children $(0.7 \%)$ having type 2 diabetes, all the children (99.3\%) had type I diabetes.

The following table presents the means and standard deviation of subscale scores by gender.

Table 3. Means and Standard Deviations of Subscale Scores

\begin{tabular}{|ll|l|l|}
\hline & & Mean & Std. Dev. \\
\hline \multicolumn{2}{|l|}{ Strengths and Difficulties } & & \\
\hline Emotional & Males & 5.68 & 2.55 \\
& Females & 6.11 & 2.54 \\
\hline Conduct & Males & 4.54 & 2.36 \\
& Females & 4.30 & 2.52 \\
\hline \multirow{2}{*}{ Hyperactivity } & Males & 5.24 & 2.44 \\
& Females & 4.57 & 2.51 \\
\hline Peer & Males & 1.84 & 1.59 \\
& Females & 1.94 & 1.81 \\
\hline Prosocial & Males & 8.20 & 1.69 \\
& Females & 7.96 & 2.02 \\
\hline \multirow{2}{*}{ Total } & Males & 17.29 & 5.99 \\
& Females & 16.91 & 6.72 \\
\hline
\end{tabular}

\section{Statistical Analysis}

\subsection{The Demographic Variables:}

\section{Child Gender:}

There is a significant difference between males and females with respect to the child age $(p=.021)$ whereas the other demographic variables show no difference with respect to the child gender. The mean score of the child age is significantly higher for females (10.431).

\section{Nationality}

There is a significant difference between Kuwaiti and Non-Kuwaiti with respect to child age $(p=.02)$, the number of brothers who have diabetes $(p=.001)$, and the family income $(p=0.00)$ where is the mean is significantly higher for the Kuwaiti group in the three cases. The other demographic variables show no difference with respect to the nationality.

3. Does Any of Parents have diabetes? (Yes\No):

There is a significant difference between the two groups with respect to the child age $(p=.039)$. The mean child age of the first group (Yes) is significantly higher than the second group (No). The other demographic variables show no difference with respect to this variable.

\subsection{The SDQ Subscales}

1. Child Gender:

There is a significant difference between males and females with respect to the hyperactivity subscale
( $p=.016$ ) whereas the other subscales show no difference. For the hyperactivity subscale, the mean score is significantly higher for males.

2. Nationality:

There is a significant difference between Kuwaiti and Non-Kuwaiti with respect to the hyperactivity subscale (p $=.007)$ whereas the other subscales show no difference. For the hyperactivity subscale, the mean score is significantly higher for Non-Kuwaiti.

3. Does Any of Parents have diabetes? (Yes\No):

There is a significant difference between the two groups with respect to the peer subscale $(\mathrm{p}=.004)$. However, there is some weaker indication of significant difference with respect to the hyperactivity subscale $(\mathrm{p}=.058)$ and the total score $(p=.058)$. The mean score for the first group (Yes) is significantly higher than the second group (No).

\section{Respondent Gender}

There is a significant difference between the two groups with respect to the emotional $(\mathrm{p}=.006)$ and peer $(.043)$ subscales. The female respondents have mean scores significantly higher than the mean scores of the male respondents with respect to the emotional and peer subscales.

\subsection{The Internal Consistency}

The internal consistency of the SDQ for this sample, using Cronbach's alpha coefficient, was 0.59. For the SDQ subscales, the Cronbach's alpha coefficient for the total difficulty scores was 0.72 , whereas for the five subscales were prosocial subscale 0.51 ; hyperactivity subscale 0.49 ; emotional subscale 0.53; conduct subscale 0.61 ; and the peer subscale 0.27 . The internal consistency of the SDQ has also been investigated in many countries (e.g.UK [5], German [14], Holland [19], Sweden [26], Bangladeshi [18], and Finnish [15]). The results across different countries supported the internal consistency of the SDQ.

\subsection{Item-total and Item-subscale Correlations}

Correlations of items to subscales and items to total difficulties scale are shown in Table 4.

The item-total correlations coefficients (last column) were negative on all prosocial items and positive on all other items. The highest correlations between single items and total scale were found "Nervous" (.594), "Easy to be angry" (.545), "Fights with others" (.515), and "Lies and cheats" (.513). The lowest item-total correlation was found on the item "Has at least one good friend" (.068).

Correlation analysis on the item-subscale level revealed that all items had the highest correlations to their respective subscales of origin. The item correlations on the prosocial behavior $(r=.471-.648)$. For the emotional problem items, the item correlations were $(r=.561-.615)$, and on the hyperactivity problems scales (.545-.685). Finally, on the peer problems scale, the item correlations were $(r=.340-.636)$.

Further, it was noticed that "Nervous" (emotional) with a correlation coefficient of 0.456 to the conduct problems subscale. "Easy to be angry" with a correlation of 0.416 to 
the emotional problems subscale. "Obedient" (Conduct) with a correlation to hyperactivity problems subscale of 0.366 and of -0.393 to the prosocial subscale. "good attention" (Hyperactivity) with a correlation of 0.358 to the conduct problems subscale, and "ridicule from other children" (Peer) with a correlation of 0.382 with the conduct problems subscale.

\subsection{The Subscales Correlations}

Subscale-subscale and subscale-total correlation coefficient according to Pearson were calculated. Table 5 presents correlations between the five subscales of the SDQ. Each subscale correlated significantly $(\mathrm{p}<0.01)$ with every other subscale.

Table 4. Correlations of items to subscales and items to total difficulties scale (Pearson's correlations coefficients). Note that the prosocial subscale does not contribute to the total sum

\begin{tabular}{|c|c|c|c|c|c|c|}
\hline & Subscales & & & & & Total scale \\
\hline & Prosocial & Emotional & Conduct & Hyperactivity & Peer & \\
\hline \multicolumn{7}{|l|}{ Prosocial subscale } \\
\hline Considerate of other people's feeling & $.648^{*}$ & -.083 & $-.272 *$ & $-.257 *$ & $-.194 *$ & $-.291 *$ \\
\hline Shares readily with other children & $.608^{*}$ & $-.189 *$ & $-.221 *$ & $-.159 *$ & $-.153 *$ & $-.270 *$ \\
\hline Helpful if someone is hurt, upset of feeling ill & $.584^{*}$ & -.088 & $-.192 *$ & $-.186^{*}$ & $-.204 *$ & $-.236 *$ \\
\hline Kind to younger children & $.629 *$ & $-.127 *$ & $-.213^{*}$ & $-.166^{*}$ & $-.214^{*}$ & $-.258 *$ \\
\hline Often Volunteers to help others & $.471^{*}$ & .047 & .02 & -.113 & $-.191 *$ & -.074 \\
\hline \multicolumn{7}{|l|}{ Emotional subscale } \\
\hline Often complains of headaches, ....etc & -.057 & $.561 *$ & $.218^{*}$ & $.135^{*}$ & $.184^{*}$ & $.407 *$ \\
\hline Worried & $-.150 *$ & $.606 *$ & $.149 *$ & $.216^{*}$ & $.238 *$ & $.442 *$ \\
\hline Often unhappy & -.015 & $.615 *$ & $.153^{*}$ & $.192 *$ & -.013 & $.376^{*}$ \\
\hline Nervous & $-.282 *$ & $.593 *$ & $.456 *$ & $.286^{*}$ & $.229 *$ & $.594 *$ \\
\hline Many fears, easily scared & -.038 & $.574 *$ & -.013 & .018 & $.123 *$ & $.263 *$ \\
\hline \multicolumn{7}{|l|}{ Conduct subscale } \\
\hline Often has temper tantrums or hot tempers & $-.236 *$ & $.416^{*}$ & $.574 *$ & $.241^{*}$ & $.233^{*}$ & $.545^{*}$ \\
\hline Generally obedient & -.393 & .102 & $.610^{*}$ & $.366^{*}$ & $.194^{*}$ & $.465^{*}$ \\
\hline Often fights with others & $-.201 *$ & $.202 *$ & $.685^{*}$ & $.309 *$ & $.183 *$ & $.515 *$ \\
\hline Often lies and cheats & -.130 & $.252 *$ & $.693 *$ & $.264 *$ & $.164^{*}$ & $.513^{*}$ \\
\hline Steals from home, school & -.057 & .013 & $.545 *$ & $.254 *$ & .099 & $.338 *$ \\
\hline \multicolumn{7}{|l|}{ Hyperactivity subscale } \\
\hline Restless, overactive, cannot stay still for long & .024 & .035 & $.207^{*}$ & $.434 *$ & -.033 & $.250 *$ \\
\hline Constantly fidgeting or squirming & $-.248 *$ & $.262 *$ & $.287 *$ & $.621 *$ & .135 & $.488^{*}$ \\
\hline Easily distracted, concentration wanders & $-.235^{*}$ & $.254^{*}$ & $.221^{*}$ & $.606 *$ & .100 & $.448^{*}$ \\
\hline Thinks things out before acting & $-.208^{*}$ & .105 & $.246^{*}$ & $.563 *$ & $.183^{*}$ & $.406^{*}$ \\
\hline Good attention & $-.181^{*}$ & $.150 *$ & $.358^{*}$ & $.635^{*}$ & $.149 *$ & $.483^{*}$ \\
\hline \multicolumn{7}{|l|}{ Peer subscale } \\
\hline Loneliness & $-.183^{*}$ & $.245^{*}$ & .035 & .023 & $.440 *$ & $.242 *$ \\
\hline Has at least one good friend & -.111 & -.090 & .014 & .042 & $.340 *$ & .068 \\
\hline Liked by other children & $-.252 *$ & $.116^{*}$ & $.205^{*}$ & .102 & $.491 *$ & $.299 *$ \\
\hline Picked on or bullied by other children & $-.201^{*}$ & $.259 *$ & $.382 *$ & $.174^{*}$ & $.605^{*}$ & $.479 *$ \\
\hline Gets on better with adults than with other children & $-.123 *$ & .072 & .057 & .104 & $.636^{*}$ & $.261^{*}$ \\
\hline
\end{tabular}

Table 5. Subscale-subscale and subscale-total correlation coefficients

\begin{tabular}{|c|c|c|c|c|c|c|}
\hline & Emotional & Conduct & Hyperactivity & Peer & Prosocial & Total \\
\hline Emotional Pearson - Correlation & & $.317^{* *}$ & $.284^{* *}$ & $251^{* *}$ & $-0.177^{* *}$ & $.679^{* *}$ \\
Sig (2-tailed) & 1 & .000 & .000 & .000 & .002 & .000 \\
\hline Conduct Pearson - Correlation & $.317^{* *}$ & & $.461^{* *}$ & $.277^{* *}$ & $-.322^{* *}$ & $.762^{* *}$ \\
Sig (2-tailed) & 000 & 1 & .000 & .000 & .000 & .000 \\
\hline Hyperactivity Pearson - Correlation & $.284^{* *}$ & $.461^{* *}$ & & $.186^{* *}$ & $-.301^{* *}$ & $.730^{* *}$ \\
Sig (2-tailed) & .000 & .000 & 1 & .001 & .000 & .000 \\
\hline Peer Pearson - Correlation & $.251^{* *}$ & $.277^{* *}$ & $.186^{* *}$ & & $-.316^{* *}$ & $.545^{* *}$ \\
Sig (2-tailed) & .000 & .000 & .001 & 1 & .000 & .000 \\
\hline Prosocial Pearson - Correlation & $-0.177^{* *}$ & $-.322^{* *}$ & $-.301^{* *}$ & $-.316^{* *}$ & \multicolumn{2}{c|}{$-.402^{* *}$} \\
Sig (2-tailed) & .002 & .000 & .000 & .000 & 1 & .000 \\
\hline Total Pearson - Correlation & $.679^{* *}$ & $.762^{* *}$ & $.730^{* *}$ & $.545^{* *}$ & $-.402^{* *}$ &. \\
Sig (2-tailed) & .000 & .000 & .000 & .000 & & .000 \\
\hline
\end{tabular}

$* * \mathrm{P}<0.01$. 
The prosocial subscale correlated inversely to the other subscales especially to the conduct problems (-0.322), peer (-0.316), and hyperactivity subscales $(-0.301)$, but also to total difficulties score $(-0.402)$. All subscales are highly correlated to the total score. The emotional, conduct, hyperactivity, and peer subscales correlations to the total score were, respectively, 0.679, 0.762, 0.730, and 0.545 . The hyperactivity subscale correlated strongly to the conduct problems subscale (0.461); the emotional problems subscale correlated fairly strong to the conduct problems subscale $(0.317)$ but weaker to the hyperactivity problems subscale $(0.284)$ and peer problems subscale (0.251). The conduct problems subscale correlated also fairly strong to the peer problems subscale $(0.277)$.

It should be noticed that the most strongly correlation (0.461) is between the conduct and hyperactivity subscales. In addition, the prosocial subscale correlated most strongly with the conduct subscale (-0.322).

\subsection{Factorial Analysis}

To investigate the factor structure of the SDQ, exploratory factor analysis has been conducted using the SPSS principal components with varimax rotation. The principal component analysis results in 8 factors with eigenvalues over than one, explaining 54.3\% of the variance. However, a varimax rotated solution with a specified number of 5 factors explaining $41.3 \%$ of the variance was easier to interpret. The results are given in Table 6.

The first three factors were the conduct subscale, prosocial subscale, and emotional subscale. The hyperactivity items are loaded on the fourth and fifth factors. The items: "Easily distracted, concentration wanders", "Thinks things out before acting", and "Good attention" were loaded heavily on the fourth factor. The two items "Restless, overactive, cannot stay still for long" and" Constantly fidgeting or squirming” were loaded on the fifth factor. The strongest factor was the conduct explaining $10.2 \%$. The second and third factors explained, respectively, $8.8 \%$ and $8.5 \%$ of the total variance. The fourth and fifth factors explained $7.9 \%$ and $6 \%$, respectively, of the total variance.

The problem was with peer subscale. The two peer items: "Liked by other children and Picked on or bullied by other children" are loaded highly on the Conduct factor. In addition, the two peer items "Loneliness" and Gets on better with adults than with other children are loaded on the prosocial factor. The fifth peer item "Has at least one good friend" was loaded on the fifth factor.

Table 6. Principal Component's analysis with varimax rotation

\begin{tabular}{|c|c|c|c|c|c|}
\hline \multicolumn{6}{|l|}{ Subscales } \\
\hline & factor 1 & Factor 2 & Factor 3 & Factor 4 & Factor 5 \\
\hline \multicolumn{6}{|l|}{ Conduct subscale } \\
\hline Often has temper tantrums or hot tempers & .509 & & & & \\
\hline Generally obedient & .391 & & & & \\
\hline Often fights with others & .580 & & & & \\
\hline Often lies and cheats & .598 & & & & \\
\hline Steals from home, school & .489 & & & & \\
\hline \multicolumn{6}{|l|}{ Prosocial subscale } \\
\hline Considerate of other people's feeling & & .467 & & & \\
\hline Shares readily with other children & & .125 & & & \\
\hline Helpful if someone is hurt, upset of feeling ill & & .598 & & & \\
\hline Kind to younger children & & .501 & & & \\
\hline Often Volunteers to help others & & .609 & & & \\
\hline \multicolumn{6}{|l|}{ Emotional subscale } \\
\hline Often complains of headaches, ...etc & & & .322 & & \\
\hline Worried & & & .556 & & \\
\hline Often unhappy & & & .443 & & \\
\hline Nervous & & & .548 & & \\
\hline Many fears, easily scared & & & .500 & & \\
\hline \multicolumn{6}{|l|}{ Hyperactivity subscale } \\
\hline Restless, overactive, cannot stay still for long & & & & & .676 \\
\hline Constantly fidgeting or squirming & & & & & .365 \\
\hline Easily distracted, concentration wanders & & & & .641 & \\
\hline Thinks things out before acting & & & & .545 & \\
\hline Good attention & & & & .668 & \\
\hline \multicolumn{6}{|l|}{ Peer subscale } \\
\hline Loneliness & & .294 & & & \\
\hline Has at least one good friend & & & & & .123 \\
\hline Liked by other children & .414 & & & & \\
\hline Picked on or bullied by other children & .626 & & & & \\
\hline Gets on better with adults than with other children & & .237 & & & \\
\hline
\end{tabular}




\subsection{Discriminant Analysis}

Discriminant analysis is aimed at finding weighted linear functions of the predictor variables. These discriminant linear functions are used to classify objects into distinct groups according to their observed characteristics. This is usually done by calculating the scores of the linear functions. In addition, it is of interest to determine the predictor variables that contributes significantly to the linear discriminating functions.

\subsection{Empirical Results}

The analysis was conducted using a stepwise selection procedure. Since we have three groups (Normal, borderline, and abnormal), two discriminant functions were extracted. These two functions (shown down) were used to classify the diabetic children into one of the three groups.

The first function is

$$
\begin{aligned}
Z_{1} & =-4.623-0.352 \text { child gender }+0.312 \text { emotional } \\
& +0.356 \text { conduct }+0.253 \text { Hyperactivity }+0.267 \text { peer }
\end{aligned}
$$

The second function is

$$
\begin{aligned}
Z_{2} & =-1.791+1.255 \text { child gender }-0.043 \text { emotional } \\
& +0.219 \text { conduct }-0.264 \text { Hyperactivity }+0.217 \text { peer }
\end{aligned}
$$

To determine whether the two discriminant functions are significant in separating patients in the three groups we found that the first function explains $99.2 \%$ of the total variance and the chi-square test of the Wilks' lambda is significant $(\mathrm{P}=000)$. In contrast, the second function explains only $0.8 \%$ of the total variance and the chi-square test of the Wilks' lambda is not significant $(\mathrm{P}=.171)$.

To know which variables have the greater impact we examine the standardized canonical discriminant functions. Recall that the second function was not significant. For the first function, the emotional factor has the greatest impact (.644) followed by the conduct factor (.639), hyperactivity (.505), peer (.410), and child gender (-.174).

Since the three centroids are significantly different the first function will do a good job discriminating between the three groups. This result has been illustrated by the following scatterplot.

\section{Canonical Discriminant Functions}

\begin{tabular}{|c|c|c|c|c|c|c|}
\hline \multirow{2}{*}{\multicolumn{3}{|c|}{ Total code }} & \multicolumn{3}{|c|}{ Predicted Group Membership } & \multirow[b]{2}{*}{ Total } \\
\hline & & & Normal & Borderline & abnormal & \\
\hline \multirow{6}{*}{ Original } & \multirow{3}{*}{ Count } & Normal & 88 & 4 & 0 & 92 \\
\hline & & Borderline & 11 & 28 & 3 & 42 \\
\hline & & Abnormal & 0 & 2 & 162 & 164 \\
\hline & \multirow{3}{*}{$\%$} & Normal & 95.7 & 4.3 & 0.0 & 100.0 \\
\hline & & Borderline & 26.2 & 66.7 & 7.1 & 100.0 \\
\hline & & Abnormal & 0.0 & 1.2 & 98.8 & 100.0 \\
\hline \multirow{6}{*}{ Cross Validation } & \multirow{3}{*}{ Count } & Normal & 87 & 5 & 0 & 92 \\
\hline & & Borderline & 12 & 26 & 4 & 42 \\
\hline & & Abnormal & 0 & 3 & 161 & 164 \\
\hline & \multirow{3}{*}{$\%$} & Normal & 94.6 & 5.4 & 0.0 & 100.0 \\
\hline & & Borderline & 28.6 & 61.9 & 9.5 & 100.0 \\
\hline & & Abnormal & 0.0 & 1.8 & 98.2 & 100.0 \\
\hline
\end{tabular}

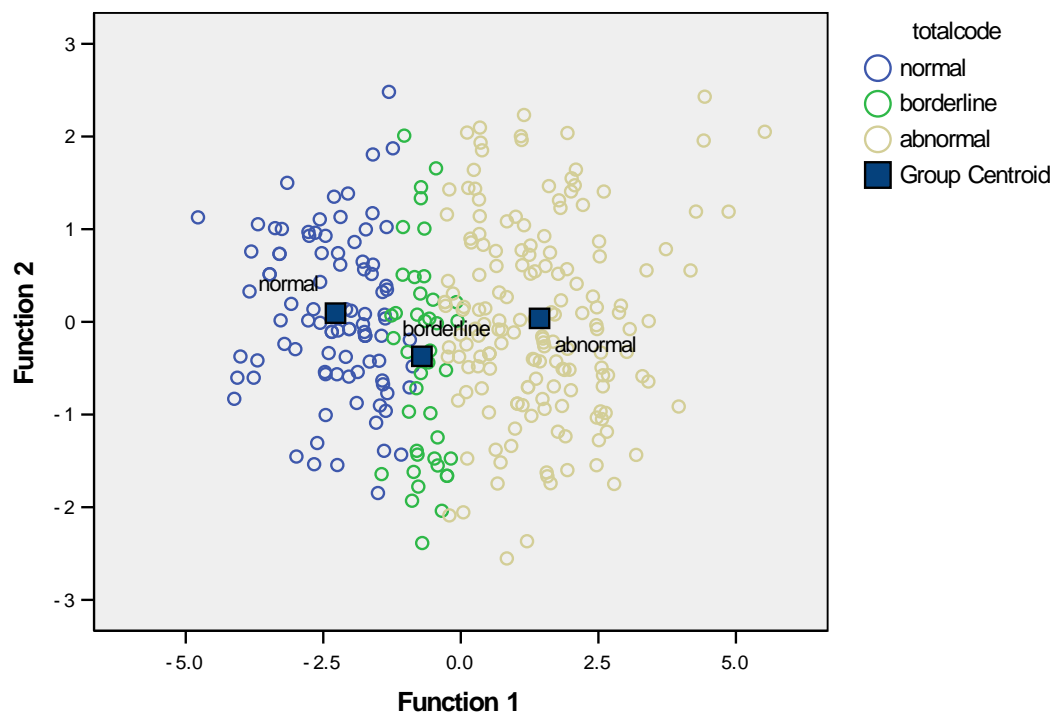

The classification results are shown in the following table. This table is called a confusion matrix.

Table 7. Confusion Matrix

Hits (correct classifications) Ratio $=(278 / 298)(100)=93.29 \%$.

Errors $=(20 / 298)(100)=6.71 \%$. 


\section{Conclusions}

Diabetes has a great impact on the emotional and behavioral characteristics of the diabetic children in Kuwait. According to the total difficulties scores, the results showed that $69.1 \%$ of the children have overall mental health problems (55\% abnormal and $14.1 \%$ borderline). The highest two percentages $(82.4 \%$ and $74.6 \%)$ were, respectively, for the emotional and conduct problems. Subscale-subscale and subscale-total correlation coefficient according to Pearson were all significant. All subscales are highly correlated to the total score. The discriminant analysis indicates that $93.3 \%$ of the original grouped cases were correctly classified into the three groups (Normal, borderline, and abnormal).

\section{Acknowledgements}

We are grateful to Dr. Anwar Alkhring for her permission to use the data and to the Statistical Consultation Unit in the college of Business Administration at KUWAIT University for its effort to get this permission.

\section{References}

[1] Goodman R., "The Strengths and Difficulties Questionnaire: a research note. Journal of Child Psychology and Psychiatry, 38, pp. 581-586, 1997.

[2] Corathers SD, Kichler J, Jones NH, Houchen A, Jolly M, Morwessel N, Crawford P, Dolan LM, Hood KK. Improving depression screening for adolescents with type 1 diabetes. Pediatrics.2013; 132(5): e1395-e1402

[3] De Groot M. Depression and diabetes. In: Young-Hyman D, Peyrot M, editors. Psychosocial care for people with diabetes. Alexandria, VA: American Diabetes Association; 2012. pp. 1-16.

[4] Jaser SS. Psychological problems in adolescents with diabetes. Adolescent Medicine. 2010; 21: 138-151.

[5] Kanner S, Hamrin V, Grey M. Depression in adolescents with diabetes. Journal of Child and Adolescent Psychiatric Nursing. 2003; 16(1): 15-24

[6] Maia AC, Braga-Ade A, Paes F, Machado S, Nardi AE, Silva AC. Psychiatric comorbidity in diabetes type 1: A cross-sectional observational study. Revista da Associação Médica Brasileira. 2014; 60(1): 59-62.

[7] Roy T, Lloyd CE. Epidemiology of depression and diabetes: a systematic review. Journal of Affective Disorders. 2012; 142(Suppl): S8-S21.

[8] Cury CR, Golfeto JH, "Strengths and Difficulties Questionnaire (SDQ): a study of school children in Ribeirao Preto", Revista Brasilieira de Psiquiatr 25:139-145.

[9] Goodman R., "Psychometric properties of the Strengths and Difficulties Questionnaire". J Am Acad Child Adolesc Psychiatry, 40: pp. 1337-1345, 2001.

[10] Goodman R., Ford T, Simmons H, Gatward R, Meltzer H "Using the Strengths and Difficulties Questionnaire (SDQ) to screen for child Psychiatric disorders in a community sample" $\mathrm{Br} J$ Psychiatry 177, pp. 534-539, 2000.

[11] Goodman R., Renfrew D, Mullick M., "Predicting type of Psychiatric disorder from Strengths and Difficulties Questionnaire (SDQ) scores in child mental health clinics in London and Dhaka" Eur Child Adolesc Psychiatry, 9: pp. 129-134, 2000.

[12] Goodman, A. and Goodman R., "Strengths and Difficulties Questionnaire as a Dimentional Measure of Child Mental Health” J Am Acad Child Adolesc Psychiatry. 2009, 48: 400-403.

[13] Grey M, Whittemore R. and Tamborlane W., "Depression in Type I diabetes in children: natural history and correlates" J Psychosomat Res. 53, pp. 907-911, 2002.
[14] Hawes, D. and Dadds, M., "Australian data and psychometric properties of the Strengths and Difficulties Questionnaire" Australian and New Zealand Journal of Psychiatry, Vol. 38, pp. 644-651, 2004.

[15] Kalsen, H., Woerner, W., Wolke, D., Meyer, R., Overmeyer, S., Kaschnitz, W., Rothenberger, A., and Goodman, R., "Comparing the German Versions of the Strengths and Difficulties Questionnaire (SDQ-Deu) and the Child Behavior Checklist" European Child \& Adolescent Psychiatry, Vol.9, No. 4, pp. 271-276, 2000.

[16] Mullick, M. and Goodman, R. "Questionnaire screening for mental health problems in Bangladeshi children: a preliminary study" Soc Psychiatry Psychiatr Epidemiol, Vol. 36, pp. 94-99, 2001

[17] Smedje, H., Broman, JE., Hetta, J., and Knorring, AI., "Psychometric properties of a Swedish version of the "Strengths and Difficulties Questionnaire" European Child and Adolescent Psychiatry, Vol. 8, pp. 63-70, 1999.

[18] Woerner, W., Fleitlich-Bilyk, B., Martinussen, R., Fletcher, J., Cucchiaro, G., Dalgalarrondo, P., Lui, M., and Tannock, R., " The Strengths and Difficulties Questionnaire overseas: Evaluations and applications of the SDQ beyond Europe" Eur Child \& Adolesc Psychiatry, Vol. 13, Supplement 2: pp. 47-54, 2004.

[19] Woerner W, Becker A, Rothenberger A: Normative data and scale properties of the German parent SDQ. Eur Child Adolesc Psychiatry. 2004, 13 Suppl 2: II3-10.

[20] Woerner W, Becker A, Rothenberger A: Normative data and scale properties of the German parent SDQ. Eur Child Adolesc Psychiatry. 2004, 13 Suppl 2: II3-10.

[21] Goodman R, Meltzer H, Bailey V: The Strengths and Difficulties Questionnaire: a pilot study on the validity of the self-report version. Eur Child Adolesc Psychiatry. 1998, 7: 125-130.

[22] van Widenfelt BM, Goedhart AW, Treffers PD, Goodman R: Dutch version of the Strengths and Difficulties Questionnaire (SDQ). Eur Child Adolesc Psychiatry. 2003, 12: 281-289.

[23] Malmberg M, Rydell AM, Smedje H: Validity of the Swedish version of the Strengths and Difficulties Questionnaire (SDQSwe). Nord J Psychiatry. 2003, 57: 357-363.

[24] Ronning JA, Handegaard BH, Sourander A, Morch WT: The Strengths and Difficulties Self-Report Questionnaire as a screening instrument in Norwegian community samples. Eur Child Adolesc Psychiatry. 2004, 13: 73-82.

[25] Obel C, Heiervang E, Rodriguez A, Heyerdahl S, Smedje H, Sourander A, Guethmundsson OO, Clench-Aas J, Christensen E, Heian F, Mathiesen KS, Magnusson P, Njarethvik U, Koskelainen M, Ronning JA, Stormark KM, Olsen J: The Strengths and Difficulties Questionnaire in the Nordic countries. Eur Child Adolesc Psychiatry. 2004, 13 Suppl 2: II32-II39.

[26] Marzocchi GM, Capron C, Di Pietro M, Duran TE, Duyme M, Frigerio A, Gaspar MF, Hamilton $H$, Pithon G, Simoes A, Therond C: The use of the Strengths and Difficulties Questionnaire (SDQ) in Southern European countries. Eur Child Adolesc Psychiatry. 2004, 13 Suppl 2: II40-II46.

[27] Dickey WC, Blumberg SJ: Revisiting the factor structure of the strengths and difficulties questionnaire: United States, 2001. J Am Acad Child Adolesc Psychiatry. 2004, 43: 1159-1167.

[28] Bourdon KH, Goodman R, Rae DS, Simpson G, Koretz DS: The Strengths and Difficulties Questionnaire: U.S. normative data and psychometric properties. J Am Acad Child Adolesc Psychiatry. 2005, 44: 557-564.

[29] Palmieri PA, Smith GC: Examining the structural validity of the Strengths and Difficulties Questionnaire (SDQ) in a U.S. sample of custodial grandmothers. Psychol Assess. 2007, 19: 189-198.

[30] Mathai J, Anderson P, Bourne A: Comparing psychiatric diagnoses generated by the Strengths and Difficulties Questionnaire with diagnoses made by clinicians. Aust N Z J Psychiatry. 2004, 38: 639-643.

[31] Almaqrami MH, Shuwail AY: Validity of the self-report version of the strengths and difficulties questionnaire in Yemen. Saudi Med J. 2004, 25: 592-601.

[32] Alyahri A, Goodman R: Validation of the Arabic Strengths and Difficulties Questionnaire and the Development and Well-Being Assessment. East Mediterr Health J. 2006, 12 Suppl 2: S138-S146.

[33] Samad L, Hollis C, Prince M, Goodman R: Child and adolescent psychopathology in a developing country: testing the validity of the strengths and difficulties questionnaire (Urdu version). Int $\mathrm{J}$ Methods Psychiatr Res. 2005, 14: 158-166. 
[34] Koskelainen, M., Sourander, A., and Kaljonen, A., "The Strengths and Difficulties Questionnaire among Finnish school-aged children and adolescents" European Child and Adolescent Psychiatry" Vol. 9, pp.277-284, 2000.

[35] Michelle M. Garrison, Wayne J. Katon and Laura P. Richardson, "The Impact of Psychiatric Comorbidities on Readmissions for Diabetes in Youth" Diabetes Care, Vol. 28, 9, pp. 2150-2154, 2005.

[36] Murris, P., Meesters, C., and Van den Berg, F., "The Strengths and Difficulties Questionnaire (SDQ). Further evidence for its reliability and validity in a community sample of Dutch children and adolescents" European Child \& Adolescent Psychiatry, Vol. 12, No. 1, pp. 1-8, 2003.

[37] Hirsh, H., Coen, M.H., Mozer, M.C., Hasha, R. and Flanagan, J.L, "Room service, AI-style,” IEEE intelligent systems, 14 (2). 8-19. Jul.2002.

[38] T. Eckes, The Developmental Social Psychology of Gender, Lawrence Erlbaum, 2000. [E-book] Available: netLibrary e-book. 